\title{
O ESTADO NAS MARGENS E AS MARGENS DO ESTADO: AÇÕES POLÍTICAS PARA MENINOS EM CONDIÇÃO DE RUA USUÁRIOS DE CRACK
}

\author{
THE STATE IN THE MARGINS AND THE MARGISN OF THE STATE: \\ PUBLIC ACTION FOR CRACK ADDICTED HOMELESS BOYS
}

\author{
Beatriz Brandão ${ }^{1}$
}

\begin{abstract}
RESUMO
O universo dos meninos em situação de rua e usuários de crack revela-se como um eixo fundamental no âmbito das políticas públicas. Nesse cenário, há um hiato entre a ação política e o que se refere à assistência e ao cuidado desses meninos, em que o desnivelamento é verificável em duas vertentes antagônicas nas políticas sociais: o da inclusão e o da repressão. A inclusão se insere na abordagem dada pelos Direitos Humanos, enquanto a repressão abarca atitudes de contenção e punição. Esse trabalho atua na perspectiva de aprofundar o conhecimento acerca das estratégias de enfrentamento dessa problemática, por meio da análise teórica de como se dá a atuação do Estado em um ponto que se encontra na margem social.
\end{abstract}

Palavras-chave: Biopolítica. Meninos de rua. Usuários de crack.

\begin{abstract}
The universe of the boys on the streets and crack users reveals itself as a fundamental in the context of public policy. In this scenario, there is a gap between policy and action with regard to assistance and care of these children, in which the deflection is observed in two strands antagonistic social policies: the inclusion and repression. The inclusion fits into the approach given by Human Rights while repression embraces attitudes of restraint and punishment. This work acts in view of deepening the knowledge about the coping strategies of this problem, through qualitative analysis of how is the performance of the State at a point that lies on the social fringe.
\end{abstract}

Keywords: Biopolitics. Street Children. Crack users.

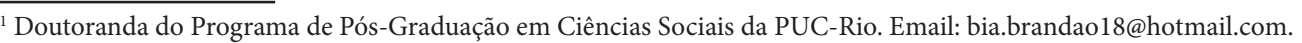




\section{Introdução}

Esse artigo propõe uma apresentação do quadro de tratamento político e assistencial destinado a meninos em situação de rua usuários de crack, tentando pensar como ocorre a dialética entre o Estado e suas margens. Para compor esse panorama, analisamos a atuação do Estado em suas margens, partindo da discussão foucaultiana sobre biopolítica, bem como do aporte teórico específico do objeto em questão: os meninos de rua.

A partir dessa matriz, buscamos compreender a política do social e o social como política, e no interior desses dois parâmetros analisamos os fios e as conexões entre cidade e ação política. Para abordagem teórica partimos do livro "Antropologia das Margens do Estado", que questiona trabalhos antropológicos em diferentes regiões para refletir sobre o que teria constituído a etnografia do Estado imbuído em práticas, lugares e linguagens considerados à margem do Estado-Nação.

No livro, as autoras Das e Poole (2004) tentam desvincular a ideia das margens a partir do território, ou da condição espacial, para dar entrada a outro viés: as margens pela vida precária. Mostra como a vida precária é objeto de construções morais, e de que modo se criam fronteiras de construções morais no espaço público. Devido à condição dualista da cidade é difícil a aproximação com o Estado. Dessa forma, é necessário tentar evitar grandes dicotomias e não fixar dualismos (por exemplo: asfalto/favela), o que dificulta se perceber os liames das relações que se estabelecem nas margens. Isso significa não ver o mundo em blocos mas em configurações. Interessa ver os movimentos do Estado por sua microabsorção e suas microrrelações, ou seja, relativizar a ideia de universalidade, percebendo como ele é pensado localmente, como é realizado e respondido pelas populações.

Nessa perspectiva, temos acesso a três abordagens possíveis para se discutir a ideia de margens. A primeira refere-se a pessoas insuficientemente integradas à lei, o que reflete na política de integração. Nesses territórios, o Estado entra com a atuação de transformação, tentando modificar sujeitos que estão fora da lei (unruly) para sujeitos dentro da lei

${ }^{2}$ DAS, Veena; POOLE, Deborah. Anthropology in the Margins of the State. Santa Fé, Oxford: School of American Research Press/ James Currey, 2004. (lawful). Pensando na situação do Rio de Janeiro, é possível encontrar práticas semelhantes na tentativa de "pacificação" em favelas, que no discurso oficial são territórios que necessitam passar por uma (re) administração para adequação aos padrões da formalidade.

A segunda abordagem foca no caráter de legibilidade e ilegibilidade (legibility and illegibility), que se relaciona à leis e aos regulamentos do Estado. Tal questão reflete na documentação e classificação pessoal da população, que de alguma forma incidem no controle de sujeitos e territórios por meio dessas práticas. No entanto, o pensamento de que o Estado se constrói em função de sua legibilidade não procede; pelo contrário, suas ideias vão se desfazendo por meio da ilegibilidade de suas próprias práticas. Assim, entendemos que as margens não são inertes, há criatividade, reação e construção de valores. Isso ocorre porque a lógica que opera entre o legal e o ilegal é opaca para si mesmo, não sendo possível prever o percurso social. As leis entram em suas ilegalidades na configuração de relações reais, tendo o espaço da margem como espaço de subjetivação.

A última diz respeito à conexão entre leis, disciplinas e corpos, no entendimento do poder que o Estado exerce além dos espaços, ou seja, sobre os corpos, no poder de gestão da vida. Para essa interpretação, são utilizados os conceitos de biopolítica ${ }^{3}$ e biopoder. Biopoder é compreendido como o poder

\footnotetext{
${ }^{3}$ Resumidamente, um dos legados da obra de Foucault é o resultado das análises sobre "poder". Em meados da década 1970, o autor se dedicou a analisar a relação do poder "soberano" sobre os corpos dos seus "súditos", em que o primeiro detinha o poder de vida, ou seja, poderia matar os segundos. Porém, no século XIX, no contexto ocidental, concretiza-se um processo iniciado pelos menos dois séculos antes, de um poder sobre a vida; em que o soberano pensado na figura do Estado teria o poder de "fazer" viver e "deixar" morrer. Tudo isso estaria relacionado pelo desenvolvimento do poder disciplinar e do gerenciamento sobre o fenômeno população que surgiu no período. No século XVII, surgiram técnicas de poder centradas no corpo individual por meio de procedimentos disciplinares que asseguravam a distribuição espacial dos corpos individuais (sua separação, seu alinhamento, sua colocação em série e em vigilância) que "produziriam" corpos úteis por meio do exercício e treinamento. Apesar de esse poder se exercer basicamente dentro de instituições, não se restringia a esses espaços e se espalhava para toda a sociedade (sociedade disciplinar). Foucault destaca que no século XVIII se consolidou outra tecnologia de poder que não excluiu a primeira técnica disciplinar, mas integra e se utiliza desta, e que se configura em outro nível. Essa nova tecnologia se dedica igualmente a agir no corpo, não ao corpo-homem, mas ao homem ser vivo. Nesse sentido, esse poder se propõe a atuar no âmbito da massa-global e é afetada por processos de conjunto próprios da vida, como por exemplo, o nascimento, a morte, a reprodução, doença, fome etc.; é o que Foucault chamou de "biopolítica" da espécie humana, que vai construir e se utilizar de uma infinidade de saberes/poderes para melhor gerir uma determinada população, ou populações específicas.
} 
que penetra nas ramificações sociais, tentando definir um padrão de normalidade, em que as categorias que não se enquadram são chamadas de "anormais". Essa conceituação remete ao que Foucault (2008) denomina "sociedade de segurança". Isto é, esse padrão de normalidade se conecta à noção de norma, que determina que os indivíduos sujeitem seus corpos a um padrão denominado normal.

A segurança, sem proibir nem prescrever, mas dando-se evidentemente alguns instrumentos de proibição e de prescrição, a segurança tem essencialmente por função responder a uma realidade de maneira que essa resposta anule essa realidade a que ela responde-anula, ou limite, ou freie, ou regule. Essa regulação no elemento da realidade é que é, creio eu, fundamental nos dispositivos de segurança. (FOUCAULT, 2008, p. 61).

Os dispositivos de segurança agem na perspectiva de "normalizar" a sociedade, por meio de intervenções biopolíticas. A partir dessas intervenções a vida dos sujeitos passa a ser gerida de forma global e uniforme, não em seus aspectos individuais. Por essa via, leis, códigos e constituições são formas que tornam aceitável um poder essencialmente normalizador. Portanto, utilizaremos o conceito para verificar como a população de rua se tornou um problema de ingerência urbana nas últimas três décadas, o que deu margem para o surgimento de um dispositivo para seu devido tratamento. A disciplina é um dos dispositivos que viabiliza o controle do corpo das pessoas, sendo um poder que incide nos corpos de maneira a engendrá-los; a manutenção da sociedade de produção é a dominação política do corpo.

As três noções utilizadas sugerem diferentes modos de "ocupação" das margens, mostrando que todas essas abordagens possuem relações e suas práticas se imbricam uma nas outras. O objeto estudado se insere nas três esferas. O Estado entra na realidade dos meninos que usam crack na tentativa de transformar os sujeitos "fora da lei" em sujeitos "dentro da lei”. Não obstante a esse fato, os atores "jogam" com as noções de legalidade e ilegalidade, produzindo sua própria lógica de regras, leis e justiça, fazendo daquele território marginal a localidade da prática de sua subjetividade. Na terceira esfera, que reúne lei/ disciplina/corpo, podemos inferir que o corpo dos meninos entregues ao crack é desconsiderado pelo Estado como corpo capaz e produtivo. E por meio de uma intervenção estatal direta, que atua pela internação compulsória desses usuários, as conexões que são estabelecidas os identificam na margem social, pois estão em todos os lugares, sinalizando o sentido da margem.

Para tal, distanciamo-nos da ideia de que territórios como esse são caracterizados pela ausência do Estado, a fim de buscar as formas que ele se posiciona e se refaz nesse local. Vemos, nesse cenário, uma política humanitária de dupla face, por um lado, indispensável e por outro, cria imagem de um mundo que se reduz à salvação ao corpo biológico.

\section{O Estado e suas margens}

Viabilizar um estudo sobre o Estado e sua atuação nas margens é verificar como marcos semânticos em parte se sucedem ou se antagonizam. Ao pôr em questão a reprodução do Estado, seu sistema de dominação moderno e suas margens, opera-se o conceito de segregação. Opera produzindo modalidades de relações sociais, o que oscila pela crítica interna estatal e institucional ou crítica normativa. Entender como se dá a produção particular do Estado e suas margens é compreender a política em sua perspectiva normativa e interna, o que nos permite pensar o processo de segregação nos termos de política pública. No cenário analisado, observamos a linguagem da violência urbana pautando a política pública, em detrimento da linguagem do Direito.

As margens exploradas por essa linguagem são aceitas como locais de controle "inquestionável" do Estado, pois são tidas como "selvagens e incontroladas", e nas quais a ação estatal se modifica em suas formas de ordenar e fazer leis, sugerindo que as margens são "decorrência e implicação necessária do Estado, assim como a exceção é um componente necessário da regra”. Para pensar as margens, procuramos: "reflect on how the practices and politics of life in these areas shaped the political, regulatory, and disciplinary practices that constitute, somehow, that thing we call "the state" (DAS \& POOLE, 2004, p.03) .

An anthropology of the margins offers a unique perspective to the understanding of the state, not because it captures exotic practices, but because

${ }^{4}$ Refletir sobre como as práticas e políticas de vida nessas áreas moldaram as práticas políticas, regulamentares e disciplinares que constituem, de algum modo, aquilo que chamamos de "o Estado". 
it suggests that such margins are a necessary entailment of the state, much as the exception is a necessary of the rule. (DAS \& POOLE, 2004, p. $04)^{5}$

Nos contextos marginais, o Estado age por meio de "práticas de exceção", onde as margens representam um centro de práticas que se reformulam e refundam num movimento cíclico. As práticas nessas zonas de exceção, ou de emergência, vão além dos termos de lei e transgressão, na verdade elas repousam dentro e fora da lei.

On one point, however, we differ from Agamben, for we feel that states of exception, differences between membership and inclusion, or figures that reside both inside and outside the law, do not make their appearance as ghostly spectral presences from the past but rather as practices embedded in everyday life in the present. [...] Our search for the margins often settles on those practices that seem to be about the continual refounding of law through forms of violence and authority. This refounding happens both through the sorts of power embodied by figures such as the policeman or local "boss". (DAS \& POOLE, 2004, p. 13) ${ }^{6}$.

Em meio à análise de Das e Poole (2004), vemos que a presença estatal nos locais marginais é, muitas vezes, determinada pelo uso da vigilância e violência sancionada pelo Estado, o que promove um alto custo para seus habitantes. Nesse contexto, as práticas consideradas excepcionais para a sociedade em geral são regras e parte da vida cotidiana dos territórios à margem. Na compreensão do uso da vigilância e violência, Das e Poole buscam o diálogo com Weber sobre o monopólio do uso legítimo da força física a fim da manutenção da ordem estatal:

A compulsory political organization with continuous operations will be called a "state" in so far as its administrative staff successfully upholds

\footnotetext{
${ }^{5}$ Uma antropologia das margens oferece uma perspectiva única para a compreensão do Estado, não porque ele capta práticas exóticas, mas porque sugere que essas margens são uma vinculação necessária do Estado, assim como a exceção é uma condição necessária da regra.

${ }^{6}$ Em um ponto, porém, diferimos de Agamben, sentimos que os estados de exceção, as diferenças entre sociedade e inclusão ou figuras que residem dentro e fora da lei, não fazem o seu aparecimento como presenças espectrais, fantasmas do passado, mas sim como práticas incorporadas na vida cotidiana, no presente. Nossa pesquisa acerca das margens, muitas vezes se instala em tais práticas que parecem ser sobre a refundação contínua de lei, por meio de formas de violência e de autoridade. Esta refundação acontece tanto através dos tipos de poder encarnados por figuras como o policial ou "chefe" local.
}

the claim to the monopoly of the legitimate use of physical force in the enforcement of its order. (Weber, 1978, p. 54). Weber also emphasized that use of force in any other type of organization would be considered legitimate only if it was permitted by the state or prescribed by it. Thus, "the claim of the modern state to monopolize the use of force is a essential to it as its character of compulsory jurisdiction and continuous operation". (DAS \& POOLE, 2004, p. 07) ${ }^{7}$

Numa concepção acerca da atuação contemporânea há que se atentar para uma questão importante que nos é recolocada na discussão das autoras: a heterogeneidade das populações provenientes das margens. Esse ponto deve ser trazido à tona e reconduzido, pois há um pensamento vigente no Estado que pressupõe as margens como territórios homogêneos e estáveis. Há, desse modo, um tratamento igual para indivíduos desiguais, ou seja, indivíduos diferentes e com necessidades distintas, o que propala ações e políticas que não atenuam a desigualdade.

É exatamente esse caráter heterogêneo que promove as "lacunas" entre o legal e o ilegal, que se dá pela produção de formas diversificadas de linguagens para reformular sua relação e seu diálogo com o Estado. Por tal fato, as margens não se constituem em comunidades inertes, abertas ao controle do Estado, ao contrário, elas delineiam seus futuros em relação ao próprio Estado ${ }^{8}$.

Os personagens desses cenários interpretam o Estado para além de suas categorias de "legal, justo ou impessoal", criando fronteiras entre o legal e o "extra" legal, o legal e o real, o que sugere uma visão distinta de justiça. Tal justiça é uma produção peculiar de suas experiências tidas em seus "universos locais", no qual estão postos em relações desiguais

\footnotetext{
${ }^{7}$ A organização política obrigatória com operações contínuas é chamada de "Estado" na medida em que seu pessoal administrativo defende, com sucesso, o direito ao monopólio do uso legítimo da força física na execução de sua ordem (WEBER, 1978, p. 54). Weber também enfatizou que o uso da força em qualquer outro tipo de organização seria considerada legítima apenas se fosse autorizada pelo Estado ou por ele fixado. Assim, "a afirmação do Estado moderno para monopolizar o uso da força é essencial a ele como seu caráter de jurisdição obrigatória e operação contínua".

${ }^{8}$ É nessa busca de um lugar diante do Estado que ocorre uma ressignificação da linguagem formal e legal, em que os meninos de rua se inserem. Inseremse porque montam suas estratégias - próprias da margem - para buscarem recursos de negociação com a ação estatal. Nesse sentido, recorremos a Goffman (1988) e seu conceito de estigma, entendendo que a população de rua, que ocupa as margens, é tida como "comunidade estigmatizada" e que, por isso, precisa "manipular" seu estigma para buscar um lugar no cenário social.
} 
diante do Estado. Na verdade, são suas vivências cotidianas que moldam as noções de justiça e lei, muitas vezes em dissonância com o conceito de justiça das representações de espaços oficiais.

Por isso, a presença do Estado é conflituosa: ela se tenciona com o imaginário das margens sobre a distinção entre legal e ilegal. Isso ocorre, também, porque a falta de clareza e legibilidade das regras não se aplica somente à sociabilidade das margens, mas, antes, a uma falta de compreensão dos próprios gestores, encarregados de executar tais regras e regulações. Assim, Das e Poole demonstram como as fronteiras entre o legal e o ilegal são mais tênues (e mais complexas) do que parecem. Destacamos, portanto, a característica "quase permanente" do estado de exceção em contextos marginais, o que permite que o Estado penetre na vida da comunidade, porém continue com seu papel indefinido.

Contudo, é aí, quando vemos esses "espaços de exceção", que é possível perceber a criatividade das margens, que criam suas próprias alternativas de ação política. Apesar de receberem categorias "patologizantes", os contextos marginais não se submetem a esses conceitos passivamente. Ao invés disso, elas buscam, entre as brechas das leis, suas estratégias de sobrevivência e "autogerência". Partindo desse ponto forte, é possível investigar os modos de fortalecimento das populações dos contextos marginais ${ }^{9}$.

Diante dessa exposição, pensamos como é a atuação do Estado nesses espaços constituídos às margens sociais e territoriais, que são sancionados pelo uso legítimo da força, por práticas de violência. Com o foco nos meninos moradores de rua e usuários de crack, procuramos entender como a população desse território promove a linguagem de sua própria justiça ao tentar se posicionar diante das fronteiras já formadas. E de que forma o poder público age, não somente na área espacial que se encontram, mas em seus corpos, como veremos adiante num diálogo com Foucault.

\footnotetext{
${ }^{9}$ Essa interpretação mais global nos remete ao caso micro desse trabalho: a relação entre os meninos de rua com seus atores externos. Dessa forma, como seu espaço marginal temos a rua. É ela que se coloca como a referência de muitos valores, mesmo que postos de forma dilapidada. Somente a rua permite que, por meio das brechas das leis estatais, os meninos se tornem os promotores de suas ordens, regras e leis, formando um específico código simbólico de sociabilidade. Esses são apontamentos preliminares da pesquisa, são hipóteses, que serão verificadas em campo.
}

\section{O crack, o menino e a política}

O universo do crack e suas disposições tem sido alvo para operações políticas e análises constantes. Entretanto, para prosseguir tais análises é necessário dar a elas o percurso correto; nesse caso, é não respaldar a droga como a causa mas como a consequência: não é a droga que leva para o caminho da miséria e sim a miséria que, muitas vezes, direciona a vida deles à dependência. Desse modo, não é o crack que traz os meninos à rua mas uma situação de exclusão, que se constitui num fenômeno "integrado por processos de vulnerabilidade, fragilização, precariedade e ruptura dos vínculos sociais em cinco dimensões: econômico-ocupacional, sociofamiliar, da cidadania, das representações sociais e da vida humana" (ESCOREL, 1999, p. 17).

Esse equívoco de interpretação e avaliação discorre, de forma direta, na formulação da atuação e dos dispositivos que serão utilizados pelo Estado. No caso da população de rua temos a divisão de três eixos analíticos: como foi constituída historicamente, contestada politicamente e regulada institucionalmente. Para responder tais questões, utilizamos o conceito foucaultiano de dispositivo a fim de descrever como essa população é gerida. Nesse sentido, para Foucault, dispositivo é:

Em primeiro lugar, um conjunto decididamente heterogêneo que engloba discursos, instituições, organizações arquitetônicas, decisões regulamentares, leis, medidas administrativas, enunciados científicos, proposições filosóficas, morais, filantrópicas. Em suma, o dito e o não dito são os elementos do dispositivo. O dispositivo é a rede que se pode estabelecer entre estes elementos.

Em segundo lugar, gostaria de demarcar a natureza da relação que pode existir entre esses elementos heterogêneos. Sendo assim, tal discurso pode aparecer como programa de uma instituição ou, ao contrário, como elemento que permite justificar e mascarar uma prática que permanece muda; pode ainda funcionar como reinterpretação desta prática, dando-lhe acesso a um novo campo de racionalidade. Em suma, entre estes elementos, discursos ou não, existe um tipo de jogo, ou seja, mudanças de posição, modificações de funções, que também podem ser muito diferentes.

Em terceiro lugar, entendo dispositivo como um tipo de formação que, em determinado momento 
histórico, teve como função principal responder a uma urgência. O dispositivo tem, portanto, uma função estratégica dominante [...] (FOUCAULT, p. 244, 1979).

Trazendo o conceito para a realidade dos meninos de rua, temos a presença de um "dispositivo de assistência social" arquitetado pelo poder público e que se configura de forma mais pontual, localizado em torno de problemas que afetam diretamente o governo, ou seja, que são de ordem política. Ao focar nas práticas, poderes e saberes que circundam os moradores de rua atendidos por esse dispositivo, direcionamo-nos para uma rede que se conforma de maneira muito particular. Tal escolha se deu por esse dispositivo apresentar uma urgência atual: a retirada da rua, às vezes forçada, das pessoas que nela moram.

$\mathrm{O}$ dispositivo revela-se como um mecanismo na engrenagem do gerenciamento de uma determinada parcela da população e favorece o funcionamento do conceito foucaultiano de biopolítica da população, que pode ser utilizado para a compreensão do fenômeno de gerenciamento da população em situação de rua. Os dispositivos articulam, então: instituições, processos de subjetivações e regras que se concretizam a partir de relações de poder.

Apesar do dispositivo em voga tentar "moldar" os moradores de rua conforme lhe traga benefícios operacionais, dentro desse espectro biopolítico há algo "que faz com que a vida e seus mecanismos entrem no domínio dos cálculos explícitos, e faz do poder-saber um agente de transformação da vida humana; não é que a vida tenha sido [no caso dos moradores de rua em questão] exaustivamente integradas em técnicas que a dominem e gerem; ela lhes escapa continuamente" (FOUCAULT, p. 131, 1979).

A literatura que trabalha com moradores de rua acaba por priorizar aspectos de ausências e instigam análises da atuação disciplinar e biopolítica sobre esses "corpos-espécies" viventes das ruas brasileiras. A obrigatoriedade da superação das necessidades biológicas pode forçar, apesar de não ser o único motivo, essas pessoas a viverem sob tutela do Estado, de instituições assistenciais ou filantrópicas, cujos corpos de certa forma devem pertencer a um "Soberano", ou seja, um poder que atue e regule a vida desses "inúteis socialmente".

Os meninos que vivem de perambular nas ruas são reconhecidos justamente como inúteis na esfera social. No que podemos dizer que eles são funcionais? $\mathrm{Na}$ visão geral, eles vivem às custas de roubos e roubam, simplesmente, para alimentar os vícios. São aqueles que, aparentemente, não contribuem em nada com a economia e, apenas, dilapidam a "ordem social", ou seja, seres dispensáveis de qualquer convívio. No entanto:

Mesmo aí, um raciocínio tenaz poderia se aplicar a uma ginástica surpreendente. O seu modelo teórico poderia ser o Foucault de Vigiar e punir. O conceito-chave poderia ser o de 'delinquência útil', pelo qual Foucault analisa um aparente paradoxo: a prisão, apesar de ter sido considerada um fracasso desde seu aparecimento, sempre mostrou uma renitente persistência. Assim, o autor, numa típica formulação antidualista, se pergunta: "O pretenso fracasso não faria então parte do funcionamento da prisão?". A partir daí Foucault se empenha em demonstrar como a prisão, ao reproduzir delinqüentes em vez de recuperá-los, na verdade produz uma espécie de mundo do crime que, em oposição à boa sociedade - de burgueses, mas também de proletários - vai servir de álibi para a manutenção e o incremento da repressão que mantém o sistema em funcionamento. (OLIVEIRA, 1997, p. 55).

Mesmo sem contribuir diretamente para a economia de produção, eles são úteis na esfera moral, servem como o antiexemplo para os filhos da classe média, como a formação do estereótipo de inimigo e de apartação. Assim, caracteriza-se a ação política e institucional, que tenta defender a sociedade desses "criminosos potenciais ou de fato", que transmitem o risco. Todavia, a escolha por tal filosofia política prejudica todo processo de sua carreira moral. Segundo Bauman (1999) e Wacquant (2001), apud Fridman (2008), a "criminalização da pobreza" tornou-se a "política social" da contemporaneidade:

A política social mencionada é uma forma de dizer que a sociedade não tem mais interesse em reeducar para o trabalho, para a produtividade ou para a disciplina. [...] Processa-se agora a "limpeza", a "higiene social", ou seja, a eliminação da "impureza social". O destino dos "consumidores falhos" (outro conceito de Bauman associado à mesma condição de não fazer parte do jogo) é o lixo, assim como eletrodomésticos cujo reparo dos defeitos é mais caro que um novo exemplar. Vigiar e punir? Não, deixar definhar (FRIDMAN, 2008, p.82). 
A forma demonstrativa contemporânea que se mostra para essa realidade é o uso do crack. O apelo que temos, e que se manifesta no senso comum, é que a vida na rua é a do consumidor de crack. Já não são mais tratados como crianças e adolescentes mas como drogados, e essa mudança transforma a forma de atuação e intervenção, levando para uma área que ultrapassa o direito. Isto é, transforma-se a identidade dos meninos para justificar uma ação autoritária. Essas ações nos remetem à ligação entre margens e ações políticas relacionadas à violência, como dizem Das e Poole (2004, p. 07):

key to this aspect of the problem of margins is the relationship between violence and ordering functions of the state. Informed as it is by a particular picture of human nature, European political theology has bestowed the state with both the quality of transcendence and a related monopoly over violence (see Abrams, 1998) ${ }^{10}$.

O crack veio dar lógica e sentido a uma política que une violência e vigilância de corpos. De forma paradoxal, há uma forte presença e vigilância desses corpos, porém a vigilância responde a um objetivo de política higienista, que age na retirada da pobreza e disciplinarização dos corpos como sustentáculo do modelo que alimenta e reproduz as instituições do Estado. Hoje, a política de "acolhimento involuntário" não é uma política de acolhimento, e sim, num protocolo de abordagem, que não fere apenas os Direitos Humanos para crianças, mas também o próprio trabalho realizado pela prefeitura.

As ações repressivas desenvolvem e fixam as fronteiras de construções morais no espaço público, o que torna o crack um instrumento de criminalização da pobreza, usado como ataque à população em situação de vulnerabilidade. A política de acolhimento involuntário se mostra como um eufemismo do que é, na verdade, um recolhimento compulsório. O Estado está presente no território marginal dos usuários, mas essa "nova" presença do Estado (munida do poder da polícia) modifica a dinâmica da rua. Logo, para além de se discutir que é preciso "limpar" as ruas, faz-se necessário discutir políticas que fica-

\footnotetext{
${ }^{10}$ A chave para este aspecto do problema das margens é a relação entre violência e funções de ordenação do Estado. Informado como é por uma determinada imagem da natureza humana, a teologia política europeia concebeu o Estado com a qualidade da transcendência e um monopólio sobre a violência relacionada (ver ABRAMS, 1998).
}

rão, sobretudo o que leva os sujeitos à condição de rua, e como esses são levados ao consumo do crack, perpetuando o ciclo de "inviabilidade" dos corpos e de direitos estruturais.

O olhar sobre estas crianças e adolescentes como um problema continua presente. Ainda hoje predominam respostas inadequadas e ações repressoras por parte do poder público, representadas pelas operações de "controle urbano" e de "recolhimento" de crianças e adolescentes das ruas. Tais ações violam deus direitos humanos, previstos em diversos artigos do Estatuto da Criança e do Adolescente (ECA). Rebatizada de ações de "acolhimento" e realizadas pelo poder público geralmente de forma violenta, estas práticas higienistas desconsideram os motivos pelos quais os meninos passam a utilizar a rua como espaço de referência, perpetuando o exercício da criminalização da pobreza vigente desde os tempos do Brasil Colônia. Não se tendo conseguido atingir as raízes do problema, ele continua firmemente estabelecido. (RIZZINI, 2010, p. 14).

Por conseguinte, a ação política se dá na ênfase da repressão em detrimento da abordagem da inclusão. Além disso, falta uma rede de articulação das ações dentro de um conjunto que debele o caso como de polícia e o entenda na contingência da política socioeconômica. Essa problemática é complexa e necessita da atuação e direção do Estado, que deve unir a assistência social com a área de saúde e de segurança pública, tratando as demandas de modo intersetorial, não isolando o problema como um caso de culpabilização dos sujeitos, por exemplo. É claro que este é apenas um ponto de se pensar essa questão que se imbrica à ordem estabelecida pelo Estado que viabiliza a produção de sujeitos "descartes" e "invisíveis", caçando e criminalizando não os componentes que levam ao consumo e distribuição das drogas e das situações de miséria, mas punindo a quem nela - miséria - se encontram.

\section{Conclusão}

Os meninos em situação de rua e a cracolândia são epígrafes da margem estabelecida a partir da vida precária e de territórios estigmatizados. Tendo por base a análise de Das e Poole (2004), podemos ver as formas de abordagem e de gerência do Estado junto a essa população heterogênea. Dessa forma, 
os espaços que os meninos utilizam para habitar ou fazer uso de sua droga são balizados pelo uso da vigilância e da violência sancionada pelo Estado, transformando-se - como explicitado pelas autoras - numa "zona de emergência" em que perfazem seu percurso entre o legal e o ilegal.

O próprio uso do crack faz parte desse processo de construção dos limites legais e extralegais e, consequentemente, da construção de si. A existência desses "farrapos humanos" tem uma força política inaudita e pode funcionar como um ponto de partida, uma âncora, para crítica nessa era da apatia, pois eles põem em questão a maioria de nossas instituições família, escola, segurança, saúde. Seja pela impossibilidade, num cenário de extrema desigualdade, de democratização do caráter integrador que comportam, seja por escancarar seu lado disciplinador e até mesmo violento. Ao fazê-lo, encontraram uma forma de vida autoabusiva - que, todavia, é tanto mais destrutiva em função da política de repressão quase ilimitada que marca a ação do Estado.

Há que se ter um tratamento adequado e que respeite a heterogeneidade do grupo, porém o tratamento não deve se mostrar em termos de dicotomias (normal e anormal) e sim de compreensão da capacidade de subjetivação desses atores, que estão imersos numa concretude social que deve ser passada em revista pelo que se apresenta na temática aqui brevemente estudada. O caráter desse fenômeno é crescente e deve ser objeto de muitas discussões, não somente acadêmica, mas deve perfilar como ponto de debate nas entidades representativas e instituições.

\section{Referências Bibliográficas}

DAS, V.; POOLE, D. Anthropology in the Margins of the State. Santa Fé, Oxford: School of American Research Press/ James Currey, 2004.

ESCOREL, S. Vidas ao léu: trajetórias de exclusão social. Rio de Janeiro: Editora FIOCRUZ, 1999.

FOUCAULT, M. Microfísica do poder. Rio de Janeiro: Edições Graal, 1979

Segurança, Território, População: curso no Collège de France (1977-1978). Tradução de Claudia Berliner. São Paulo: Martins Fontes, 2008.

Vigiar e punir. Petrópolis: Vozes. 1977.

FRIDMAN, L.C. "Morte e vida favelada". In Machado da Silva, Luiz Antonio (org.). Vida sob cerco - violência e rotina nas favelas do Rio de Janeiro. Rio de Janeiro: Nova Fronteira/Faperj, 2008.

GOFFMAN, E. Estigma: notas sobre a manipulação da Identidade deteriorada. Rio de Janeiro: Editora Guanabara, 1988.

OLIVEIRA, L. “Os excluídos 'existem'? Notas sobre a elaboração de um novo conceito". São Paulo: Revista Brasileira de Ciências Sociais, n.33, vol.12, fev.1997.

RIZZINI, I. Crianças e Adolescentes com direitos violados. Situação de rua e indicadores de vulnerabilidade no Brasil urbano. Rio de Janeiro: CIESPI e Puc-Rio, 2010.

Recebido em 31 de julho de 2013

Aceito em 10 de outubro de 2013 